\title{
THE PHOBIA AS THE FUNDAMENTAL FACTOR IN THE PSYCHONEUROSIS.
}

\author{
By T. H. THOMAS, Bristol.
}

Freud has said in his Introduction to Psycho-analysis, "' "The structure of psycho-analysis that we have erected is really only a superstructure, which, at some future time, must be placed upon its organic foundation".

The view here maintained is that in every psychoneurosis there is one feature that can be considered in physiological terms and can be definitely stated to arise as the result of physiological processes. That feature is the phobia.

Freud has emphasized the importance of an inherited special constitution for the future development of the neurosis, but he has not definitely postulated the organic nature of this constitution. His modification of his original view that the main causative factor in the psychoncurosis was infantile psychic trauma, and his replacement of this by the view that the actual outbreak of the neurosis was occasioned by later-formed phantasies ${ }^{2}$ of infantile traumatic experiences, would appear to be somewhat at variance with any clearly-defined hypothesis as to the organic origin of the neurosis. The existence of a phantasy implies the pre-existence of a condition of mental stress, for which the phantasy is merely a psychic compensation. When the phantasy is called for as a release mechanism, the neurosis has already started. The factors which have given rise to the mental stress are the only factors which can have any fundamental value.

Jung has described Freud's analytic conception of the neurosis as 'one-sided', 3 and has drawn attention to the importance of a present mental conflict for the onset of neurotic symptoms. Were he less of an animist one would feel that his 'constructive' viewpoint would be of great assistance in the development of a final understanding of the neurosis. The crux of the Freudian theory is seen to be that repressed mental material exists in the unconscious, and that unconscious mental processes are typically conative in kind, and may be described as wishes. ${ }^{4}$

E. B. Holt says in the Freudian Wish, "The wish transforms the principal doctrines of psychology and recasts the science; much as the atomic theory and later the ionic theory have reshaped earlier 
conceptions of chemistry". ${ }^{5}$ He brings the wish-theory into line with behaviouristic psychology by defining behaviour in terms of specific response ${ }^{6}$ to environment, a release phenomenon occurring in the reacting organism in response to external factors. This definition suggests that a condition of internal stress is set up in the reacting organism, a motor set, ${ }^{7}$ which, when touched off, results in the reestablishment of physiological equilibrium.

The specific response as conceived by Holt is identical with the Freudian wish. According to Holt, behaviour is not necessarily a function of the immediate stimulus, except in the lowest stages of development. $^{8}$ As bchaviour evolves, any correlation between it and the stimuli immediately affecting the organism becomes increasingly remote. The immediate stimulus recedes in importance owing to the integration of reflexes.

Sherrington points out that even the simplest reflexes are purposive, and states that "the fact that a reflex action should exhibit purpose is no longer considered evidence that a psychical process attaches to it; let alone that it represents any dictate of choice or will".9

If now we regard the neurosis from the standpoint of behaviour, we shall be able to discover one of its features which is directly dependent upon environmental changes. There appears to have been a tendency, amongst writers on medical psychology, to consider the phobia as merely one out of many psychoneurotic symptoms, and rather to regard it as something to be dealt with en passant than to attach any great significance to its rôle in the psychoneurosis. If we admit, however, that the phobia is universally present and fundamental in psychoneuroses, we shall have adranced at least one step towards placing these mental illnesses on a psycho-physiological basis.

As has been so frequently insisted upon, especially by Rows, ${ }^{10}$ the phobia is invariably a conditioned reflex; i.e., the emotional state is aroused through the association, by partial correspondence, of two independent stimuli. Although Pawlow, ${ }^{11}$ in his experiments upon the dog, refers to the gastric secretion obtained as 'psychic' secretion, the reflex action itself, like other reflex actions, is a physiological phenomenon, but it is attended by conscious sensations. There is every reason to bejlieve that when a similar reaction takes place in man it depends upon similar physiological processes, the mental accompaniments being regarded as merely concomitant or epiphenomenal.

The predominant emotional accompaniment of the phobiaconstellation is seen to be fear or the more compound emotion anxiety. It is interesting firstly to consider morbid fear and anxiety 
from the viewpoints of the analytical and post-analytical schools. Freud's conclusion is shown by the following statement: "Under certain circumstances, sexual excitations arise that cannot follow their natural course of leading to either physical gratification, or conscious desire for such; being deflected from their aim they manifest themselves mentally as morbid anxiety, physically as the bodily accompaniments of this". ${ }^{12}$ Jung says: "Fear is the expression of converted libido", and "fear is the expression of an introversion .which has become neurotic". ${ }^{13}$ Introversion is a type of response which may be expressed in terms of inhibition of organized wishes or motor sets, i.e., instincts. Libido, in the sense that Jung uses it, is but another name for the wish itself. Both Freud and Jung indicate indirectly that repression or inhibition is a necessary factor in the production of fear or anxiety.

Fear is the feeling which results from a state of physiological disharmony. This disharmony arises in consequence either of the inhibition of one of the individual's instinctive processes or the mutual interference of two or more; when an instinct is inhibited the result may be anger or fear. Anger obtains when the individual's wish to assert himself is only partially inhibited. Total inhibition leads to fear-or the more compound emotion anxiety.

We may say then that when a neurotic is suffering from a phobia he is in a state of fear or instability. This fear is due to the fact that a certain portion of his environment has an increased value, owing to association with previously experienced fear-producing stimuli. His response to regain stability proves unavailing.

The phobia is the basic factor in psyehoneuroses. When it is considered from this point of view the symptomatology of the psychoneurosis follows by logical sequence. The patient becomes watchful and self-centred. These characteristic traits are modes of response specifically directed towards the exclusion of those portions of his environment which are disturbing. His field of easy response has become narrowed, and, passively, situations calculated to cause discomfort are avoided. Memory and concentration are poor because attention, again passively, is directed towards discovering those objects in the environment which should be avoided.

In every neurosis the important question to consider is, "How is the neurotic acting now?"--after the pattern of the behaviouristic question, "What is the organism doing ?" The more modern psychologists, such as McDougall ${ }^{14}$ and Trotter, ${ }^{15}$ have rightly insisted, in opposition to the older, academic psychologists, that man, a social animal, is not to be considered apart from his species. The behaviourist goes further, and states positively that man is not to be considered apart from his environment, that his conduct is in fact 
a function of his environment. If in the analysis of phobias one realizes that it is necessary to search invariably the neurotic patient's present environment for the provocative stimuli, the investigation of the neurosis is much facilitated.

Adler' bases his 'feeling of inferiority', which is a constant feature of the neurosis, and practically synonymous with Janet's ${ }^{\mathbf{1 7}}$ 'sentiment d'incomplètude', upon an organically inferior constitution. It would seem that, in a general sense, the individual with the inferior constitution is especially liable to become phobic; it is through the medium of the phobia, however, that the feeling of inferiority is arrived at. Adler calls the end which the neurotic is struggling to attain, the 'imaginary goal'. The goal is not of necessity imaginary. The neurotic has a clearly-defined goal; he is striving for precisely that feeling of power which he possessed before the onset of his symptoms. The portion of his environment with regard to which he has become phobic is a measure of his loss of power.

As a result of the feeling of inferiority the neurotic becomes irritable, suspicious, envious, etc.; his attempts to regain the necessary minimum of power fail, he perceives himself to be upon a level inferior to that of the rest of the community-his gregarious impulses are thereby obstructed; he is in a certain degree cut off from the herd. Moreover, he feels that others measure him by the same standard with which he measures himself, and naturally resents inspection and possible criticism.

The feeling of inferiority, with the resulting 'desire for power', enters also into the dream. This assists in explaining why dreams which appear terrifying are fulfilments of wishes. The neurotic is struggling to preserve his ego. Because his ego has suffered, when sleep arrives, and his higher, inhibitory centres lie dormant, the dream material appears, in visual form, to release him from his sense of inferiority. At one time he is the conqueror, the master of the situation; he has attained his mastery after a period of dire distress. Here the wish fulfilment is clear, even in the manifest content of the dream. At other times he may be the vanquished; then he derives some measure of satisfaction from the fact that the odds against him are overwhelming; thus he levers his ego into a more estimable position. It is noteworthy that in this type of dream the situations presented are often the traumatic ones which have given rise to the patient's phobias. Each of the above types of dream represents reactions on the part of the nerrous system in the direction of release from states of tension.

Ernest Jones ${ }^{18}$ criticizes, one feels with justice, Jung's conception of the unconscious as an obscure region of the mind, the content of 
which is characterized largely by neglect and oblivion. He somewhat scathingly terms it the 'limbo' conception, the unconscious part of the mind being considered as a sort of lumber-room to which various mental processes get relegated when in a state of inactivity or decay. The same remark applies, however, though in a different degree, to the Freudian theory of the neurosis, which, as one cannot fail to see, is pervaded throughout by a subtle animism. The hypothesis that there are two separate strata of the mind separated by a barrier penetrable only by means of hypnosis or psycho-analysis must surely prove in the end untenable. Further, it is difficult to see how 'ideas' and 'mental processes' can with any accuracy be said to exist below the level of consciousness. It is certain that determining neural conditions exist prior to the development of ideas; that these conditions may either give rise to ideas or be inhibited appears equally obvious. One would prefer to call them neural processes which do not attain to the level of awareness.

The acceptation of the behaviourist viewpoint with regard to both normal and abnormal psychology would do much to relieve one of the necessity for assuming the existence of an unconscious mind. The theory of repression can without difficulty be expressed in terms of inhibition of instinctive processes, such inhibition occurring when the release of a motor set or neurogram is directly obstructed; or when two or more asynergic neurograms are simultaneously stimulated; thus a soldier in the trenches may experience anxiety either when his flight into safety is directly prevented by external circumstances, or when the impulse to flee from danger conflicts with herd instincts.

As regards the Freudian theory of the universally sexual etiology of the neurosis, in which Jung concurs to the extent that "co-existing with traumatic experiences .... there is a special kind of disturbance which can only be described as a derangement in the sphere of love", 19 it is quite obvious that phobias may occur in the sexual sphere, just as they may occur in the sphere of any other instinctive process. The fact that the sexual instinct is apt, by its very nature, to be inhibited can very well account for the frequency wherewith sexuality plays its part. The conception, however, that sexuality is universal and necessarily predominant is untenable-unless it be possible that the sexual instinct is the only one man possesses.

${ }^{1}$ Frevd, S., A General Introduction to Psycho-analysis, 1920, 337.

2 Frecd, S., Selected Papers on Hysteria and other Psychoneuroses, 1920, 189.

3 .Jevg, C. .J., Collected Papers on Analytical Psychology, 1920, 392.

4 Joxes, E., Papers on Psycho-analysis, 1918, 123. 
${ }^{5}$ Holt, E. B., The Freudian Wish, 47.

${ }^{6}$ Holt, E. B., op. cit., 52.

' Holt, E. B., op. cit., 94.

${ }^{8}$ Holt, E. B. op. cit., 75.

${ }^{9}$ Sherrington, C. S., The Integrative Action of the Nerrous System, 1906, Lect. vii, 235.

${ }^{10}$ Rows and OrR, Functional Mental Illnesses, 1920, ii, 20.

11 Pawlow, J., The Work of the Digestive Glands, 1910.

12 JoNes, E., op. cit., 489.

13 Jung, C. J., op. cit., 141.

14 McDotgale, W., Introduction to Social Psychology, 1914.

15 Trotter, W., Instincts of the Herd in Peace and War, 1916.

${ }^{16}$ Adler, A., The Neurotic Constitution, 1921, 1.

17 Jaset, Pierre, Obsessions et Psychasthénie, 1903, 1, 264.

18 JoNes, E., op. cit., 122.

19 JUNs, C. J., op. cit., 363. 